\title{
Original
}

\section{Changes in Gas Permeability and Permselectivity of Natural Zeolite Disk by Heat Treatment}

\author{
by \\ Jin Cheng Zhe ${ }^{\dagger}$, Masahiro Shishido ${ }^{\dagger \dagger}$ and Masayuki TodA ${ }^{\dagger \dagger}$
}

\begin{abstract}
The changes in the gas permeability and permselectivity of natural zeolite disk by heat treatment were examined. The natural zeolite disks were fired for several hours at temperatures of 673 to $1273 \mathrm{~K}$. The gas permeability and separation factor of the disks were measured by the gas permeation experiments with nitrogen-hydrogen gaseous mixture. The pore size distributions of the disks were evaluated by mercury porosimetry. The gas permeation experiments showed that gas permeability and separation factor simultaneously improved under a proper heat treatment condition. However, the measured mean pore diameters of the heat-treated samples was found to increase as the heat treatment temperature was increased. Such phenomenon could not be interpreted with considering conventional gas molecule transport mechanism through straight pores. Based on the observations, a qualitative model for pore structure change by neck growth due to sintering was proposed to account for the simultaneous improvement of the gas permeability and separation factor.
\end{abstract}

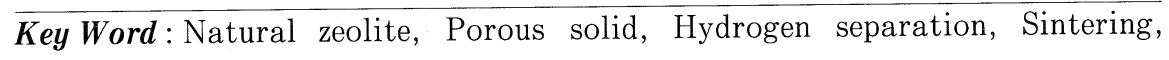
Knudsen diffusion

\section{INTRODUCTION}

Natural zeolite is a natural yielded porous material consisting of small particles of silica, alumina and zeolite. The content of the zeolite is commonly below $20 \mathrm{wt} \%$. We have had a plan to use it as a ceramic membrane or a catalyst carrier. In our previous paper ${ }^{1)}$, the natural zeolite yielded in Itaya, Yonezawa city, was found to have gas permeation selectivity based on Knudsen diffusion. This natural zeolite contains two types of zeolite; clinoptilolite and mordenite.

In the present investigation, the changes in the pore size distribution, gas permeability, and permselectivity of the natural zeolite by heat treatment were measured. The observed interesting change in gas permeation properties of the natural zeolite membrane by heat treatment is reported. Furthermore, an assumption on the mechanism of pore structure change of the natural zeolite by sintering was proposed to interpret the experimental results on the change in the characteristics of

Received August 31, 1995

† Samsung Engineering Co, Ltd. Green BLDG. 79-2, Karak-Dong, Song Pa-ku, Seoul, KOREA, 138-160

$\dagger \dagger$ Department of materials Science and Engineering, Yamagata University, 3-16, Jonan 4-chome, Yonezawa 992, JAPAN 
gas permeability and permeation selectivity by heat treatment.

\section{EXPERIMENT}

Natural zeolite yielded at Itaya in Yonezawa city was used as a sample. The constituents in the natural zeolite are summarized in Table 1 . Silica and alumina are found to be predominant. The

Table 1. Constituents of Itaya zeolite (wt\%)

\begin{tabular}{c|c|c|c|c|c|c|c}
\hline $\mathrm{SiO}_{2}$ & $\mathrm{Al}_{2} \mathrm{O}_{3}$ & $\mathrm{Fe}_{2} \mathrm{O}_{3}$ & $\mathrm{CaO}$ & $\mathrm{MgO}$ & $\mathrm{K}_{2} \mathrm{O}$ & $\mathrm{Na}_{2} \mathrm{O}$ & others \\
\hline 72.47 & 12.08 & 1.31 & 1.22 & 0.38 & 3.12 & 2.98 & 6.24 \\
\hline
\end{tabular}

natural zeolite was shaped into a disk which had $35 \mathrm{~mm}$ in diameter and $10 \mathrm{~mm}$ in thickness. The natural zeolite disks were preheated in atmosphere at $673 \mathrm{~K}$ for 2 hours and then fired for 3 hours at various temperatures in the range of 673 to $1273 \mathrm{~K}$. The diameter and thickness of the heat-treated disks were measured and then their volumetric shrinkage was evaluated. The volumetric shrinkage of the heat-treated sample was defined by

$$
\Psi=\frac{V_{0}-V_{t}}{V_{0}}
$$

where $V_{0}$ and $V_{t}$ are the volume of the zeolite disk before and after heat treatment, respectively. The heat treated and untreated disks were allowed to measure their pore size distribution by mercury porosimetry (YUASA IONICS, AUTOSCAN 60).

The gas permeability, $\beta$, and separation factor, $\alpha$, of the heat treated zeolite disks were measured under room temperature condition. The experiments were carried out with $\mathrm{H}_{2}(30 \%)-\mathrm{N}_{2}$ gaseous mixture under various applied pressures. The gas permeation rates were measured with a soap film flow meter. The hydrogen concentrations of the permeated gas were measured by gas chromatography. The separation factor was defined in this work as follows.

$$
\alpha=\frac{\chi_{2} /\left(1-\chi_{2}\right)}{\chi_{1} /\left(1-\chi_{1}\right)}
$$

Here, $\chi_{1}$ and $\chi_{2}$ are the concentrations of hydrogen in the feed and permeated gases, respectively. The gas permeability of zeolite disk was defined by

$$
\beta=\frac{Q_{P}}{(\Delta P / L) A}
$$

where $Q_{P}$ is the gas permeation rate, $\Delta P$ is the pressure difference, $L$ is the disk thickness, and $A$ is the disk area.

\section{RESULTS AND DISCUSSIONS}

\section{Shrinkage of zeolite through heat treatment}

Figure 1 shows the relation between the volumetric shrinkage of the heat-treated zeolite disks and the heat treatment temperature. In this figure, the relation between the shrinkage and the heat-treated period is also represented. The open circles and triangles represent the shrinkage after 


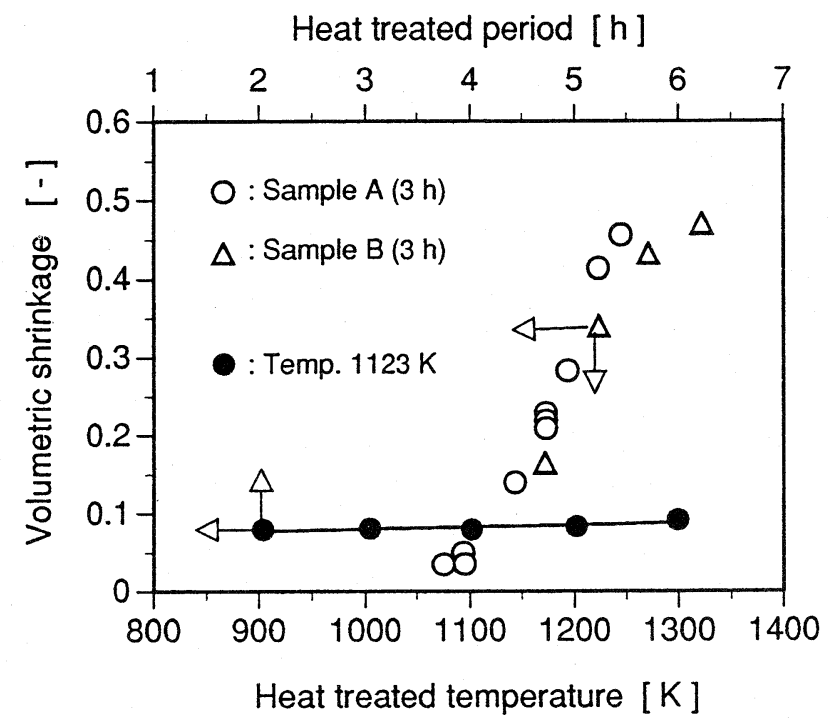

Fig. 1 Volumetric shrinkage of natural zeolite disks by heat treatment

heat treatment for 3 hours at various temperatures. These two types of plot correspond to two kinds of disks that are cut out from different two blocks. On the other hand, the solid circles refer to the time dependence of the shrinkage at $1123 \mathrm{~K}$. It is found that the shrinkage process almost completes in 2 hours under the conditions in this study. No shrinkage was observed at the heat treatment temperatures below $1123 \mathrm{~K}$. The shrinkage became significant above $1123 \mathrm{~K}$. Furthermore, no significant difference in the data between two natural zeolite blocks is observed. In addition, it was confirmed that the natural zeolite disks shrunk isotropically because the ratio between diameters before and after heat treatment is almost same as the ratio between the thicknesses before and after heat treatment. Thus, all samples maintained the original geometrical shape almost perfectly.

\section{Pore size distribution of heat-treated natural zeolite disk}

The data obtained by mercury porosimetry for the heat-treated and untreated natural zeolite disks are summarized in Table 2. The total pore volume is found to increase to a maximum value

Table 2. Pore characteristics of natural zeolite disks

\begin{tabular}{c|c|c|c|c}
\hline $\begin{array}{c}\text { Heat treated } \\
\text { temperatura }[\mathrm{K}]\end{array}$ & Pore volume $[\mathrm{ml} / \mathrm{g}]$ & $\begin{array}{c}\text { Specific surface } \\
\text { area }\left[\mathrm{m}^{2} / \mathrm{g}\right]\end{array}$ & $\begin{array}{c}\text { Averaged pore } \\
\text { diameter }[\mu \mathrm{m}]\end{array}$ & $\begin{array}{c}\text { Maximum pore } \\
\text { diameter }[\mu \mathrm{m}]\end{array}$ \\
\hline Untreated & 0.380 & 30.0 & 0.0254 & 0.0412 \\
1073 & 0.412 & 32.0 & 0.0257 & 0.0452 \\
1123 & 0.406 & 27.6 & 0.0294 & 0.0492 \\
1143 & 0.372 & 20.5 & 0.0363 & 0.0620 \\
1173 & 0.308 & 13.5 & 0.0455 & 0.0755 \\
1193 & 0.235 & 4.60 & 0.1022 & 1.170 \\
\hline
\end{tabular}


and then decrease with increasing heat treatment temperature. The specific surface area also increased with a similar trend which was observed in the pore volume as the heat treatment temperature was increased. The mean and maximum pore sizes, however, monotonically increase with an increase in the heat treatment temperature.

Figure 2 shows the pore size distributions after heat-treatment for 3 hours. These pore size distributions were obtained by differentiation of the cumulative pore volume curves for the heattreated natural zeolites. The ordinate represents the pore size distribution that was normalized by the largest peak value. The pore size distribution of the zeolite disk that was heated at $1193 \mathrm{~K}$ was quite different from those at other temperatures. It suggests that the pore structure was destroyed completely by sintering. This sample may correspond to the final stage structure of sintered powder compact defined by Coble ${ }^{2}$. Up to $1173 \mathrm{~K}$, the pore size distributions are found to be similar to each other, i.e. they have two major peaks around $0.1-0.2 \mu \mathrm{m}(1000-2000 \AA)$ and $0.02 \mu \mathrm{m}(200 \AA)$.

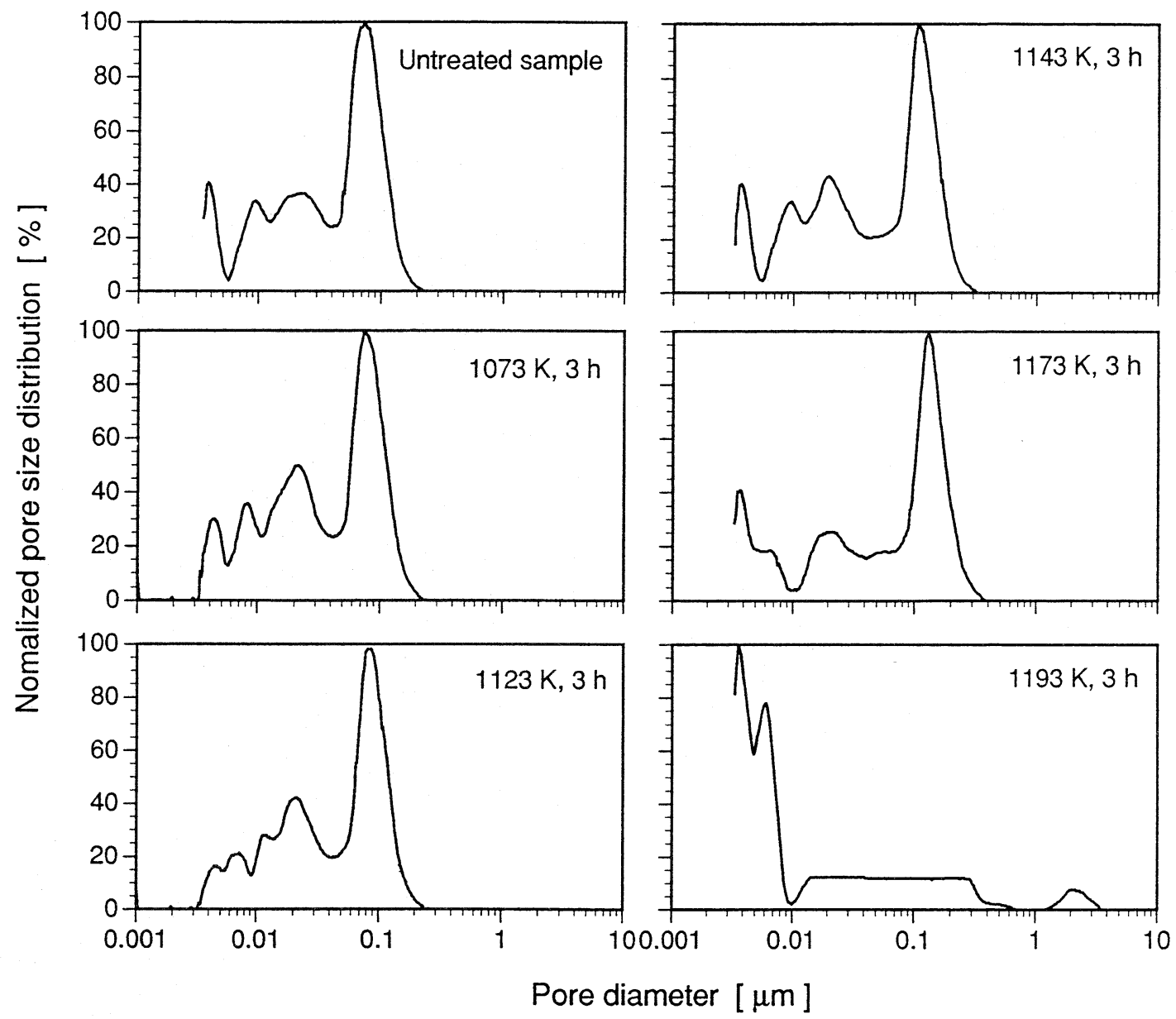

Fig. 2 Pore size distributions of heat-treated and untreated natural zeolite disks 
The former peak tends to slightly shift to a larger side with increasing heat treatment temperature while the latter peak only shows an irregular change in its height with temperature.

\section{Gas permselectivity of heat-treated zeolite membrane}

The results of the gas permeation experiments are shown in Fig. 3. The hydrogen separation selectivity of the heat-treated and untreated zeolite disks were found to increase and reach its maximum value and then decreases as the applied pressure difference was increased. The gas permeation

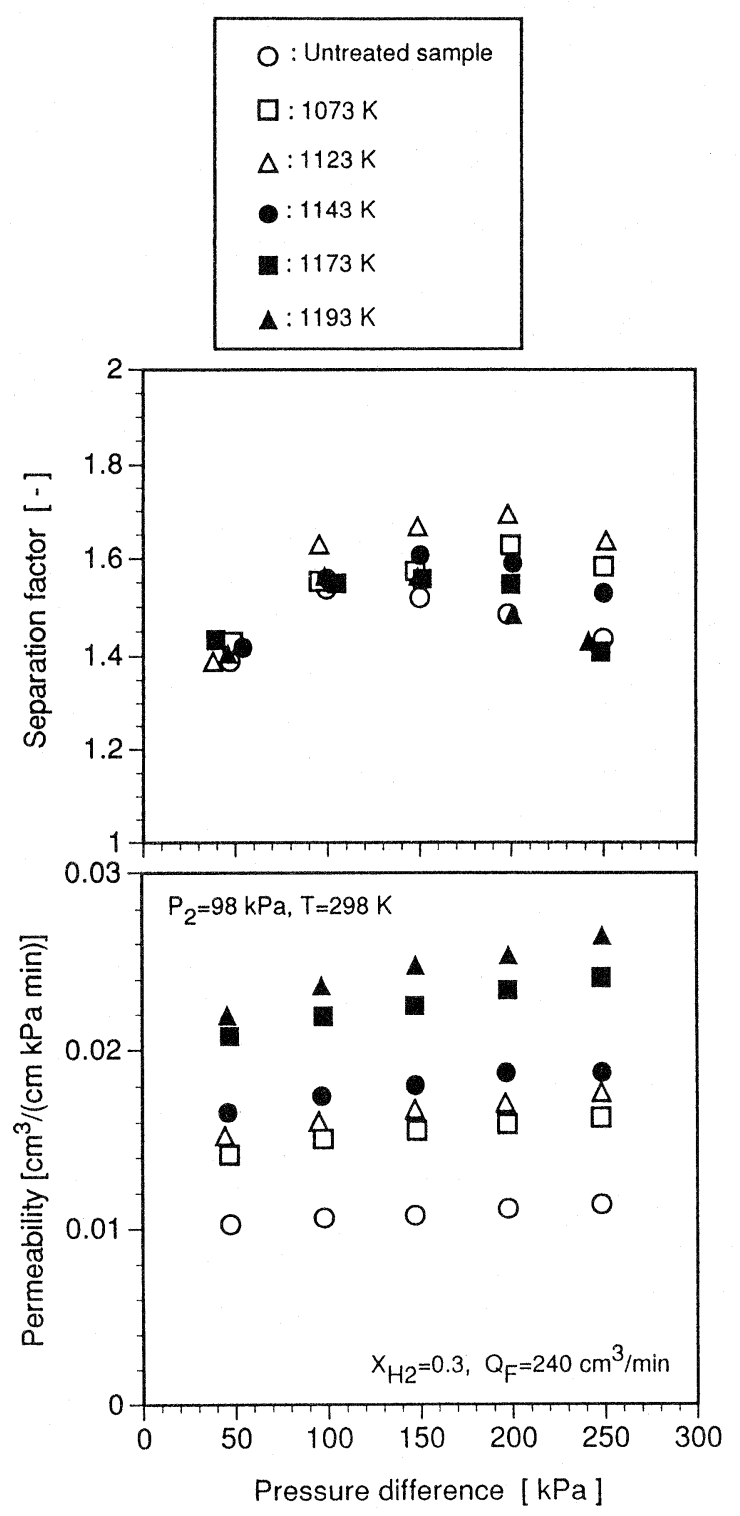

Fig. 3 Experimental results on separation factor and permeability 
rate for the hydrogen-nitrogen system increased monotonically with increasing applied pressure difference. It is found that the slope of the permeation rate against the pressure difference increased gradually with increasing heat treatment temperature. The relation between the gas permeation rate and permeation selectivity and the applied pressure difference, shown in Fig. 3, are generally observed in the gas permeation through natural zeolite ${ }^{1)}$. The most important observation here, however, is that a heat treatment condition exists at which both separation selectivity and permeability can improve simultaneously. In other words, it is possible to improve gas permselectivity without a decrease in gas permeation rate by modification of pore size distribution or pore structure by heat treatment.

For gas flow phenomena through straight micropores, as pore diameter is increased the flow mechanism changes from Knudsen regime to viscous flow. The gas permeation rate in Knudsen diffusion regime is less than that in viscous flow while in viscous flow regime the permselectivity will diminish. Hence, in most cases it is generally understood that an increase in the permeation rate due to any modification on microporous media usually results in a decline in the separation factor. In this study, as shown in Table 2, the mean pore diameter and pore volume of the natural zeolite disks increased by heat treatment. However, both permeation selectivity and permeability improved.

We considered that such interesting gas permeation characteristics of the heat-treated natural zeolite disk was resulted from the change in pore structure. Davis ${ }^{33}$ carried out a monte carlo simulation based on the perfect Maxwellian gas for the effect of geometrical modification of cylindrical pipes on molecular flow rates through them. He reported that the restricted openings of pipes increased the probability for a molecule to enter from one opening and to leave through the other. This is because in the case of the pipe with the restricted opening the solid angle to exit from the opening for the molecules entering once into the pipe is smaller than that in the case of the unrestricted opening. Based on his result of monte carlo simulation, a model for pore structure change during heat treatment is proposed in order to explain the experimental results. The model is described in Fig. 4 schematically. As shown in figure, it is assumed that both openings of the original straight pore are expanded and further a thin stopper like an orifice having a smaller opening compared to the diameter of the original pore is produced in the pore. As mentioned above, since the natural zeolite is consisted of small particles, gas permeates through a thin space among particles. Assuming natural zeolite is composed by spherical small particles, the packed particles could fuse each other at the contact points of

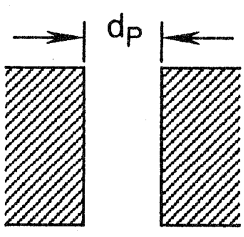

(a) Original pore structure

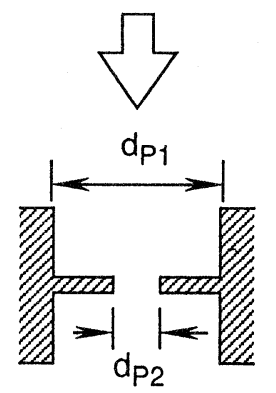

(b) Pore structure after heat treatment

$$
d_{P 1}>d_{P}>d_{P 2}
$$

Fig. 4 Pore structure change model by heat treatment 
them by heat treatment and then small opening stoppers like an orifice would be produced in the pore structure. The gas permeation resistance through such pores with modified structure would be mainly governed by the flow through a small opening of the stopper. Provided that the stopper is extremely thin and the modified pore opening become larger than that of the original pore, the effective length of pore for gas separation based on Knudsen diffusion will be reduced. In general, the permselectivity mainly depends on the pore diameter while the permeability on the pore length. Consequently, an apparent permeability through such a thin stopper would increase compared to that through the original pore. On the other hand, such a thin stopper will increase the permeation selectivity.

\section{CONCLUSION}

The determination of the change in the pore size distribution and the gas permeation properties of the heat-treated natural zeolite disks revealed that the mean pore diameter was increased by increasing heat treatment temperature. Further, the gas permeation experiments through the disks showed that permeability and gas separation factor simultaneously improved under a proper heat treatment condition. To interpret simultaneous improvement of gas permeability and permselectivity a model for pore structure change was proposed.

\section{NOMENCLATURES}

$L \quad$ thickness of natural zeolite disk [m]

$P_{1} \quad$ pressure at gas feed side $[\mathrm{kPa}]$

$P_{2} \quad$ pressure at gas permeation side $[\mathrm{kPa}]$

$\Delta P$ applied pressure difference $\left(\mathrm{P}_{1}-\mathrm{P}_{2}\right)[\mathrm{kPa}]$

$Q_{F} \quad$ gas feed rate $\left[\mathrm{cm}^{3} \mathrm{~min}^{-1}\right]$

$Q_{P} \quad$ gas permeation rate $\left[\mathrm{cm}^{3} \mathrm{~min}^{-1}\right]$

$\chi_{1} \quad$ hydrogen fraction in feed gas [-]

$\chi_{2} \quad$ hydrogen fraction in permeate [-]

$V_{0} \quad$ volume of zeolite disk before heat treatment $\left[\mathrm{m}^{3}\right]$

$V_{t} \quad$ volume of zeolite disk after heat treatment $\left[\mathrm{m}^{3}\right]$

$\alpha \quad$ separation factor [-]

$\beta \quad$ gas permeability $\left[\mathrm{cm}^{3}\left(\mathrm{~cm} \mathrm{kPa} \mathrm{min}^{-1}\right]\right.$

$\Psi \quad$ volumetric shrinkage [-]

\section{REFERENCES}

1) Toda, M., M. Shishido, M. Nakayama, T. Suzuki: J. Soc. Materials Engineering for Resources of Japan 4, 12 (1991)

2) Coble, R. L.: J. Appl. Phys., 32, 787 (1961)

3) Davis, D. H.: J. Appl. Phys., 31, 1169 (1960) 